\title{
PENSAMENTO SOCIAL BRASILEIRO, ESTUDOS ORGANIZACIONAIS E A REINVENÇÃO DO SERTÃO: UMA ENTREVISTA COM O PROF. PAULO EMÍLIO MATOS MARTINS
}

\author{
Paulo Ricardo Zilio Abdala
}

“O Brasil não é para principiantes”. A conhecida frase de Tom Jobim parece captar a essência do trabalho do Professor Paulo Emilio Matos Martins, nascido em Belém (PA) e radicado no Rio de Janeiro, Paulo Emilio reúne qualidades dignas de nota. Além de ser um pesquisador metódico e comprometido com a realidade nacional, coordenador e fundador do Núcleo de Estudos de Administração Brasileira (ABRAS) - grupo de pesquisa brasileiro mais antigo sobre Estudos Organizacionais, área Administração do Diretório de Grupos de Pesquisa (CNPq), é um professor dedicado a seus alunos e uma figura humana da maior estirpe. Também é um erudito, conhecedor da cultura mundial e nacional, figura rara nos tempos atuais, exibindo em sua biblioteca uma coleção invejável de grandes clássicos da literatura mundial, muitos dos quais afirma ter relido incontáveis vezes.

No meio acadêmico, além de fazer parte da história da Administração no Brasil, é uma das referências na articulação entre o Pensamento Social Brasileiro e os Estudos Organizacionais. Atualmente, é professor (aposentado e em atividade) do Quadro Permanente do Programa de Pós-Graduação da Universidade Federal Fluminense (PPGAd/UFF), tendo sido professor titular, por mais de vinte anos, da Escola de Administração Pública e de Empresas da Fundação Getúlio Vargas (EBAPE/FGV).

Ao longo de sua carreira, publicou mais de cinquenta artigos em periódicos, organizou uma dezena de livros, é autor de A Reinvenção do Sertão - tese de doutoramento em Administração na EAESP/FGV (1999), posteriormente publicada pelas FGV Editora (Rio de 
Janeiro, 2001) e Hucitec (São Paulo, 2018), provavelmente sua produção literária mais importante - resultado de uma obstinada pesquisa documental, bibliográfica e de campo, realizada ao longo de mais de uma década, seguindo os passos de Antônio Conselheiro e da Guerra de Canudos no sertão nordestino e buscando compreender a organização social e o sistema de poder "conselheirista" no Bello Monte (BA, 1893-1897). Alguns chegam a brincar que Paulo Emilio é um pouco Euclides da Cunha, tamanha sua identificação com Canudos e a história de Conselheiro e do povo que lá viveu e foi sacrificado. Não, à toa, entre seus muitos prêmios e títulos, encontra-se o Mérito Euclidiano, conferido em 2009 pela Casa de Euclydes da Cunha da Secretaria de Cultura do Estado do Rio de Janeiro. Diria que ele também é um pouco Conselheiro, considerando sua indignação permanente com as desigualdades e mazelas deste país e seu ímpeto em buscar, na história e nos autores brasileiros, explicações que nos façam compreender melhor e transformar a nossa realidade. Paulo Emílio é, nesse sentido, um investigador dos Estudos Organizacionais Críticos "de sinal trocado" - aludindo sua tese de doutoramento sobre a autoridade de Antônio Conselheiro como sendo a de um "coronel com o sinal trocado", ou um "coronel pelo avesso", em paródia à metáfora euclidiana do sertanejo como um "homem pelo avesso" - que subverte a tradição epistemológica do campo, marcada pelo funcionalismo, pelo culto ao estrangeiro e pela aceitação da mimesis na produção do conhecimento.

A entrevista que gerou este texto ocorreu ao longo de duas tardes em sua casa em Nova Friburgo (RJ), totalizando, aproximadamente, oito horas de gravações. A temática inicial era o Pensamento Social Brasileiro nos Estudos Organizacionais, mas falar sobre Canudos acabou se mostrando inevitável. Durante a edição deste texto, tive dúvidas sobre o quanto das muito interessantes histórias sobre sua pesquisa de campo deveria deixar na versão final. Ao fim e ao cabo mantive muitas passagens inteiras, que, juntas, terminam por formar um panorama muito interessante sobre a importância de estudar o "espaço-dinâmica organizacional" brasileiro (expressão esta cunhada pelo entrevistado) a partir do pensamento social que sobre o mesmo se produz. 
Para realizar essa entrevista tive o privilégio de ser recebido por Paulo Emilio, por um final de semana, em seu escritório de trabalho, localizado em na região serrana fluminense, em meio a Mata Atlântica. Espaço este que, além abrigar uma invejável biblioteca muito organizada e um arquivo de documentos, também reúne itens curiosos, por exemplo, um antigo gramofone em perfeito funcionamento, motivo pelo qual Paulo Emilio se refere a sua residência como sendo, também, "uma espécie de museu". Entre ótimas refeições e passeios conheci um pouco mais do homem por trás do professor. Quando começamos esta entrevista, ele perguntou se eu me importava de deixar uma trilha de jazz ao fundo, para ajudar as ideias a fluírem. Em certo momento, serviu dois copos de whisky para nos aquecer (não sei se o corpo ou o espírito). Paulo Emílio tem muito o que dizer, e diz. Espero que essa entrevista inspire outros acadêmicos na busca pelo comprometimento com a realidade nacional, pelo gosto por objetos de pesquisa que permitam o resgate de nossa história e a valorização de nossa produção intelectual. Que seja também uma lembrança perene sobre a importância da busca pela profundidade teórica e empírica, contradizendo uma realidade produtiva que empurra os acadêmicos cada vez mais rumo ao que é rápido, efêmero, passageiro e ilusório.

\section{PROFESSOR PAULO EMILIO, PARA INICIARMOS, VOCÊ PODERIA CONTAR COMO VOCÊ SE TORNOU PROFESSOR DE ADMINISTRAÇÃO?}

Primeiro eu me formei em Engenharia Mecânica e me licenciei como professor de Desenho na Universidade Federal do Pará. Ministrei aulas para os ensinos Secundário e Técnico-Industrial e exerci a engenharia por mais de uma década, em uma fase de grande crescimento econômico do país (1970/80). Trabalhei em grandes empresas de projetos industriais. Foi uma época em que nossa geração saía da escola e era desafiada a fazer tudo aquilo que ela não havia aprendido a fazer. Chegavam no Brasil as usinas nucleares, grandes hidrelétricas, plantas petroquímicas etc., equipamentos de grande porte que nunca tinham sido montados aqui; como reatores nucleares e outros equipamentos pesadíssimos. Eu me recordo agora dos estudos que realizei para a montagem das comportas da Usina Hidrelétrica de Itaipu, dos fornos da Usiminas, do vão central da Ponte Rio-Niterói etc. Tudo era gigantesco e desafiador. 
Comecei a trabalhar muito cedo como educador. Iniciei aos 18 anos de idade, ministrando aulas de Geometria Descritiva para o cursinho de vestibular onde eu havia me preparado para os exames de ingresso na Universidade. Iniciei, portanto, como professor em uma área completamente diferente da qual eu hoje atuo. Mas, de certa forma, devo a minha descoberta da Administração à Engenharia.

Muito jovem me tornei gerente de projetos em uma empresa norte-americana de engenharia e me dei conta de que a minha formação não me tinha preparado para exercer a função de gestor. Os problemas surgiam cotidianamente na minha mesa: problemas financeiros, de relações interpessoais, de negociação, de liderança de equipes multidisciplinares, etc. Fiz, então, diversos cursos na área de gestão, até que me dei conta que Administração é uma coisa muito mais séria do que o tratamento que recebe nesses programas de treinamento. Hoje, eu brinco com meus alunos: vocês estão sendo preparados para exercer o ofício dos deuses; como administradores vocês irão tomar decisões sobre destinos humanos e, se é verdade que Deus existe, o que ele faz?" (risos...). Então vocês vão exercer uma atividade divina, muito séria, muito diferente da banalidade inconsequente veiculada nos cursinhos e nas revistas do "pop management". Para concluir, ilustro: um médico luta, desesperadamente, para salvar uma vida, mas um administrador pode destruir muitas, com única decisão irresponsável.

Quando ingressei no magistério superior comecei lecionando Gestão e Avaliação de Projetos para arquitetos e engenheiros. Em paralelo, busquei uma maior qualificação na área das ciências sociais aplicadas e da Administração, até chegar aos estudos históricos e à dimensão do simbólico. Meu interesse maior, hoje, se concentra em compreender os fenômenos sociais a partir de sua multidimensionalidade e contextualização, o que me levou aos universos: antropológico, da etnografia, sociológico, político, da História, aos Estudos Organizacionais Críticos e, particularmente, ao pensamento social brasileiro e latino americano.

Abandonar a Engenharia e me dedicar exclusivamente à vida acadêmica, quando eu já era um engenheiro sênior, foi, entretanto, uma decisão muito difícil. Aquela prateleira lá em 
cima (apontando para uma prateleira de sua biblioteca), aquilo ali é o meu arquivo de trabalhos técnicos de engenharia. Eu não consigo descartar nada. Ali têm trabalhos importantes. Eu jurei, para mim mesmo, que, um dia, escreveria um livro técnico sobre a história da engenharia industrial no Brasil, e aquela coleção contém preciosos documentos históricos, registros de momentos que a minha geração - que está se retirando - viveu. Ali tem coisas fantásticas como, por exemplo, documentos dos estudos para as montagens dos: vão central (caixões metálicos) da Ponte Rio-Niterói, das comportas da Usina Hidrelétrica de Itaipu, do reator da Usina Nuclear de Angra dos Reis, do reator e de outros equipamentos de grande porte do polo petroquímico da Bahia, dos altos-fornos da ampliação e modernização do parque siderúrgico brasileiro e de outros levantamentos de cargas que, com a limitação dos equipamentos de manobra disponíveis no Brasil de então, exigiam muita criatividade e redobrado cuidado no planejamento e cálculo dessas operações.

Assim, a decisão de mudar de área de atuação profissional foi muito difícil, quando eu já era um engenheiro sênior, mas eu nunca me arrependi de havê-la tomado. Eu já estava mesmo cansado de sair correndo para dar aula e fazer isso como uma segunda atividade. Era, então o início dos anos 1980. Depois veio o curso de mestrado em Administração Pública na EBAP/FGV, o doutoramento em Administração de Empresas na EAESP/FGV e a dedicação exclusiva à Universidade.

\section{VOCÊ PODERIA FALAR UM POUCO MAIS SOBRE O INÍCIO DE SUA CARREIRA ACADÊMICA PROPRIAMENTE DITA.}

Em 1984, ano de meu ingresso na carreira docente do Ensino Superior Federal, como professor concursado da Universidade Federal Fluminense (UFF) começa, de fato, a minha maior dedicação integral à Academia e o aprofundamento no Pensamento Social Brasileiro. Eu ministrava, então, uma disciplina eletiva para o curso de graduação em Administração da UFF e propus como tema de estudos a História Administrativa do Brasil. Iniciávamos o curso com a administração brasileira do período colonial e os modelos organizacionais que o sucedem historicamente. Dessa época emerge a necessidade de historicizar o que eu denomino "espaço-dinâmica organizacional" no Brasil (público e privado) tanto do ponto de 
vista do pensamento acadêmico voltado para formação do administrador, quanto do ponto de vista dos modelos, estruturas e da sua dinâmica. Descobri, assim, que minha curiosidade em estudar esse tema não era apenas minha, já que os alunos receberam muito bem essa ideia e o projeto do ABRAS foi crescendo.

Ainda dentro dessa disciplina, depois incluída como matéria obrigatória no currículo da UFF com o nome de Administração Brasileira (1991), nasceram as primeiras pesquisas de alunos (de graduação) por mim orientadas, abrindo espaço para o surgimento de um grupo de pesquisa, então denominado Grupo de Investigação em História Administrativa do Brasil (1988). Este foi o embrião do grupo que hoje se chama Núcleo de Estudos de Administração Brasileira (ABRAS), sediado no PPGAd/UFF. Os documentos dos projetos pioneiros do ABRAS atestam que ele é o sexto grupo de pesquisa mais antigo da área de Administração no Brasil e o primeiro nos Estudos Organizacionais, de acordo com uma investigação recente (ainda inédita) feita pelo ABRAS no banco de dados do Diretório dos Grupos Brasileiros de Pesquisa do CNPq.

\section{O QUE MAIS VOCÊ GOSTARIA DE ACRESCENTAR SOBRE ESSE PERÍODO INICIAL.}

É interessante lembrar que esses esforços de pesquisa nasceram a partir de duas curiosidades minhas. Uma delas era estudar a evolução da estrutura de organização do Banco do Brasil, no seu nível institucional, desde a sua fundação no período joanino (1808) até os dias atuais, como resposta estratégica aos desafios impostos pelos múltiplos papéis desempenhados por aquela instituição financeira. Outra linha de pesquisa era voltada para estudar as organizações alternativas à burocracia. 0 que fizemos inicialmente foi listar diversas possibilidades de organizações para pesquisar, sendo que uma se destacou, tornando-se, mais tarde, minha tese de doutoramento. A ideia era analisar a organização social do Bello Monte de Antônio Conselheiro (1893-1897), por intuir que lá, provavelmente, teriam sido experienciadas formas não-burocráticas de organização. Queríamos ver até onde essa experiência teria sido participativa e, quem sabe (?), até mesmo um modelo sertanejo de autogestão. 


\section{DEPOIS VOLTAREMOS AO TEMA DE BELLO MONTE COM MAIS DETALHES. ANTES, GOSTARIA QUE VOCÊ FALASSE UM POUCO MAIS DO MOMENTO NO QUAL VOCÊ CONCENTRA SEUS ESFORÇOS NA FUNDAÇÃO GETÚLIO VARGAS, QUANDO SUA TRAJETÓRIA COMO PESQUISADOR SE CONSOLIDA.}

Como a maioria dos professores brasileiros, fui também um "auleiro", na expressão carinhosa do meu saudoso amigo o professor Theotônio dos Santos. Ministrei muito mais horas de aulas do que seria razoável em um país onde a educação é um valor social. Quando olho, hoje, a minha produção acadêmica penso que é quase um milagre. Não sei como consegui produzir tanto, com tanto tempo dedicado à sala de aula. Por isso eu digo que minha decisão de me dedicar integralmente à carreira acadêmica não foi fácil.

No início do século atual eu acumulava as funções de professor adjunto, regime de $20 \mathrm{~h}$ semanais na UFF, com as de professor titular da EBAPE/FGV (40 h); ganhava, então, no Ensino Federal, menos do que um motorista de ônibus à época. Assim, precisava acumular, legalmente, as duas pesadas cargas horárias de trabalho, ministrando aulas nas manhãs, tardes e noites e em muitos finais de semana em cursos em outras cidades, para a graduação e a pós-graduação (lato e stricto sensu), além de todas as demais atividades de orientação, pesquisa, produção acadêmica, preparação de aulas, etc. Eram tempos muito difíceis aqueles; sem reajustes salariais que repusessem a perda de poder aquisitivo da moeda imposta pela severa inflação de então. Mas, o estopim que me levou à decisão de pedir licença do Serviço Público se deu quando, ao fazer a minha declaração anual de rendimentos, descobri que devolvia muito mais do que os meus ganhos anuais da UFF para o governo. Foi, então que me licenciei, sem vencimentos da UFF, para me dedicar, exclusivamente, à Fundação Getúlio Vargas, o que me obrigou a levar comigo o grupo de investigação em História Administrativa do Brasil para aquela instituição. Já na Escola Brasileira de Administração Pública (EBAP), depois Escola Brasileira de Administração Pública e Empresas (EBAPE)/FGV, este grupo cresceu, adquiriu, maturidade acadêmica, internacionalizou-se e passou a chamar-se Programa de Estudos de Administração Brasileira (ABRAS). 
Foi na EBAPE que iniciamos nossa parceria acadêmica com o grupo Organização e Práxis Libertadora da Universidade Federal do Rio Grande do Sul, principalmente através da Professora Maria Ceci Misoczky. Estreitamos, então, os nossos laços e interesses acadêmicos comuns ampliando o uso do pensamento social e da literatura interpretativa do Brasil como referência teórica nos Estudos Organizacionais. Em comum elaboramos o projeto 0 Pensamento Social Brasileiro na Qualificação do Ensino e da Pesquisa em Administração e fomos contemplados com o seu financiamento pela CAPES. Desse projeto participou, também, como instituição convidada, a UFF que, então, trabalhava na criação do seu Programa de PósGraduação em Administração (PPGAd) com foco em Administração Brasileira e a utilização intensiva do Pensamento Social Brasileiro como tema e referência teórica de concentração.

Aprovado o projeto do PPGAd/UFF eu fui convidado para voltar à atividade naquela IES, em regime de dedicação exclusiva, e integrar-me ao seu quadro de professores. Para tanto, tive que me desligar da EBAPE/FGV, regressar à UFF e me dedicar ao seu novo programa de pós-graduação. Mais uma vez o ABRAS mudou de sede, regressando, assim, à sua instituição de origem (2012). Em 2018 celebramos o trigésimo aniversário de atividades acadêmicas contínuas desse grupo de investigação. Hoje coordenamos uma rede de parcerias nacionais (com representantes de todas as cinco regiões do país) e internacionais (principalmente, da América Latina e da Península Ibérica) com mais de uma centena de instituições associadas.

\section{É CURIOSO QUE O PENSAMENTO SOCIAL BRASILEIRO TENHA LEVAdO VOCÊ PARA LOCAIS TÃO DISTANTES FORA DO BRASIL. DE ONDE VEM ESTE INTERESSE?}

Esse fato tem a ver com o interesse nosso em focar o ato administrativo como um fenômeno histórico e culturalmente referenciado. Quando falamos de gastronomia, falamos das culinárias oriental, africana, brasileira, amazônida, etc. Isso tem a ver com o modus operandi e a "cosmogonia" que estruturam os valores dessa cultura e de sua dinâmica social. A maneira como se dá a vida organizacional é, como eu entendo, um fato cultural, e por isso, histórico e também singular. Foi essa a razão que despertou a curiosidade dos colegas latinoamericanos e ibéricos pelo Pensamento Social Latino-Americano e as nossas raízes comuns. A 
partir da constatação dessa visão, surgiram projetos de parceria internacionais: na realização de eventos, na publicação de livros e artigos, na orientação de teses e, especialmente, na contribuição do ABRAS para a criação do primeiro programa de doutoramento em Administração do Equador (Universidad Andina Simón Bolívar - UASB-EC), e na subsequente criação do Programa de Doctorado en Gestión de la Tecnologia (Escuela Politécnica Nacional - EPN-EC), também na cidade de Quito (EC). É interessante destacar que, hoje, como resultante dessa aproximação do Brasil com o Continente Sul-Americano, autores como Alberto Guerreiro Ramos, Mauricio Tragtenberg, Milton Santos, Darcy Ribeiro, entre tantos outros brasileiros, e Bolívar Echeverría, José Martí, etc., entre os pensadores de língua castelhana, são referências comuns nos trabalhos acadêmicos dessas instituições.

\section{E FALANDO EM BRASIL, SERÁ QUE VOCÊ PODERIA APROFUNDAR A TEMÁTICA DO PENSAMENTO SOCIAL BRASILEIRO COMO CAMPO DE ESTUDOS DENTRO DA ADMINISTRAÇÃO?}

Posso dizer, muito rapidamente, que a análise orientada para a realidade social brasileira supõe o estudo da memória nacional, além da interpretação das representações sociais resultantes de nossa práxis organizacional. E que essa memória invoca o Pensamento Social e as interpretações do Brasil, não apenas os de origem acadêmica, mas também aqueles que resultam da criação popular da nossa gente, incluindo aí a memória física (arquitetura, indústria, pintura etc.), oral, literária e musical. Os Sertões, por exemplo, não é um livro acadêmico. Ainda que seu autor, Euclides da Cunha, tenha alimentado o desejo de um concurso, jamais realizado, para o magistério na Escola Politécnica e ministrado apenas algumas poucas aulas no Colégio Pedro II, sua obra interpretativa do espaço-dinâmica organizacional do semiárido nordestino (Os Sertões) e da Amazônia (À Margem da História) são preciosas fontes para o conhecimento de nossa sociedade. Outros autores, como Sérgio Buarque de Holanda, Raymundo Faoro e Victor Nunes Leal foram acadêmicos e escreveram a partir da memória nacional, sendo, também, fontes importantes para a compreensão de nossa realidade. 0 primeiro, mais conhecido por sua obra Raízes do Brasil e o segundo, pelo seu Os Donos do Poder e o terceiro, por Coronelismo, Enxada e Voto. Temos, ainda, o caso singular 
do Gilberto Freyre que até hoje se discute se a sua obra é ou não uma tese científica. Se analisarmos desapaixonadamente Casa-Grande \& Senzala e os demais livros daquela trilogia, encontraremos a primeira grande obra historiográfica, na linha da École des Annales produzida no Brasil a incorporar a revolução que a historiografia havia realizado na França do início do século XX; ainda que essa obra já tenha sido, inclusive, classificada como um romance.

Nessa mesma linha, lembro agora de um trabalho de pesquisa de mestrado que orientei na UFF e que analisou fontes não acadêmicas como os registro da memória brasileira sobre a significação do trabalho na lírica da música popular brasileira do primeiro governo Vargas (1930-45 - época da regulamentação da relação capital-trabalho no Brasil e da criação da Justiça do Trabalho). Nessa investigação analisamos o discurso de 37 canções (hits musicais da época) de compositores/cantores populares importantes, como, Ataulfo Alves, Dunga, Francisco Alves, Herivelto Martins, Noel Rosa, Wilson Batista e tantos outros. As conclusões dessa pesquisa são muito curiosas: imaginávamos que o trabalho seria representado, principalmente, pela figura do trabalhador-malandro. Ao final da investigação constamos que a representação central do trabalho naquele cancioneiro surge como fonte potencial de conflito conjugal. Dito de outro modo, ora na fala do trabalhador (homem) que lamenta "carregar" nas costas uma companheira preguiçosa e perdulária, ora no lamento da trabalhadora (mulher) que tem que sustentar um companheiro malandro e gastador. Resumidamente: o trabalho revela-se, assim, como uma atividade negativa e desarmonizadora das relações conjugais/amorosas.

No PPGAd/UFF ministrei as disciplinas de Pensamento Social Brasileiro I e II, disciplinas obrigatórias desde a sua criação, onde estudamos as interpretações do Brasil, independente da área de conhecimento e das teses propostas por esses pensadores. Como são muitas estas referências, temos modificado o temário dessas disciplinas a cada semestre. Como estratégia de organização dos cursos, buscamos uma figura central a ser homenageada, por exemplo, na celebração de uma efeméride importante. Já estudamos os pensamentos de: Euclides da Cunha, em 2002 (centenário de publicação de Os Sertões); Josué de Castro, em 
2008 (centenário do autor); Victor Nunes Leal, em 2014 (centenário de nascimento do pensador); Guerreiro Ramos, em 2015 (no seu centenário de nascimento) e assim por diante. A temática desses cursos, além do pensamento da figura central do homenageado do período, é estudar, ainda, os seus prógonos, epígonos e críticos. Selecionamos aqueles que se debruçam sobre a tese central do homenageado, como, por exemplo, as categorias de desenvolvimento econômico; desigualdade social, escravidão, sociedade estamental, coronelismo, etc.

\section{A DISCIPLINA DE PENSAMENTO SOCIAL BRASILEIRO NA ADMINISTRAÇÃO É BASTANTE INCOMUM. ATÉ ONDE EU SEI SOMENTE A UFF E A UFRGS TÊM UMA EXPERIÊNCIA CONSOLIDADA EM MINISTRAR ESTE CONTEÚDO DE MANEIRA REGULAR.}

Acredito que sim. Acho que um dos desafios de ministrar essa disciplina é estar sempre atualizando sua vasta e diversa bibliografia, buscando novas possibilidades de ver nossa formação social, explorando novas ideias e novos autores. Este ano, por exemplo, introduzimos uma novidade nessas disciplinas. Analisamos a obra A Tolice da Inteligência Brasileira de Jessé Souza (2015), autor crítico das elites brasileiras e dos clássicos interpretativos do Brasil, como os antes mencionados. Trata-se uma análise centrada na tese da não superação da ordem escravocrata em nossa cultura e da "violência simbólica" que essa nos legou, tese essa muito lúcida e que encontra na figura de Joaquim Nabuco o pioneiro de sua proposição. Souza é, entretanto, um acadêmico que desqualifica alguns desses clássicos, atribuindo aos mesmos uma leitura apressada de Max Weber. Pessoalmente concordo inteiramente com essa análise que leva as elites brasileira a naturalizarem a gritante desigualdade social de nossa sociedade, mas discordo da forma como Souza classifica esses clássicos ao atribuir-lhes a denominação de "culturalistas conservadores". Sobre este assunto eu brinco com meus alunos dizendo que sou tentado a escrever um trabalho com o título: A Tolice de A Tolice da Inteligência Brasileira (risos), parodiando Marx em sua crítica à obra Filosofia da Miséria de Proudhon com a sua Miséria da Filosofia. 


\section{ESPECÍFICA, QUERIA TE OUVIR FALAR SOBRE O PENSAMENTO SOCIAL BRASILEIRO EM RELAÇÃO AO CAMPO DOS ESTUDOS ORGANIZACIONAIS NO BRASIL.}

A área de Estudos Organizacionais é muitas vezes minimizada, talvez por não constituir um conhecimento hard (duro) mas sim soft (mole), na classificação científica metaforizada pela tradição anglo-saxônica. Com certeza se você falar de sistemas de produção, mercadologia, finanças economia, etc., de mais visível tangibilidade, essas disciplinas significar-se-ão, no imaginário popular, como sendo de maior cientificidade. Acaba que o ensino dos temas aos se incluem os Estudos Organizacionais são, em geral, ministrados tragicamente nos cursos de Administração, utilizando uma literatura mimética das culturas cêntricas forâneas.

Pensadores brasileiros como Alberto Guerreiro Ramos, Maurício Tragtenberg, Fernando Prestes Motta, etc., escreveram obras pioneiras no campo dos Estudos Organizacionais Críticos sendo, de fato, os propositores avant-la-lettre da corrente dos Critical Management Studies (CMS) surgida somente algumas décadas depois no universo de língua inglesa. Também na utilização do Pensamento Social como referência na análise organizacional é destacável o pioneirismo de Guerreiro Ramos com sua obra Administração e Estratégia do Desenvolvimento: Elementos de uma Sociologia Especial da Administração, dada a conhecer em 1966, republicada, post mortem (do autor) em 1983 com o título Administração e Contexto Brasileiro, onde Ramos analisa o formalismo no Brasil a partir das contribuições de autores nacionais como: Paulino José Soares de Souza - Visconde de Uruguai (1807-1866), Machado de Assis (1839-1908), Silvio Romero (1851-1914), Alberto Torres (1865-1917), Euclydes da Cunha (1866-1909), Oliveira Viana (1883-1951) e outros.

No Brasil de hoje eu vejo com muita alegria e esperança o trabalho de alguns poucos grupos de pesquisa que buscam encarar com seriedade as interpretações do Brasil, seu pensamento social e a reflexão histórica, política e cultural sobre as organizações, desertando, assim, da mera transposição (malfeita) de culturas exóticas e compreendendo melhor nossas idiossincrasias próprias. Nós acadêmicos temos a responsabilidade de conduzir essa bandeira, devemos deixar muito claro para os nossos alunos e orientandos essa singularidade 
e combater o que um outro intérprete do Brasil, chamado Nélson Rodrigues, denominou "complexo de vira-lata".

\section{SIM, E INFELIZMENTE, MUITOS PESQUISADORES E DOCENTES QUE CONHECEM NOSSA TRADIÇÃO DECIDEM VIRAR DE COSTAS PARA TODO ESTE LEGADO, INCLUSIVE ADOTANDO POSIÇÕES DE DESPREZO OU CRÍTICAS SEM FUNDAMENTO.}

Claro, nenhuma mudança se faz saltando degraus. Quando olho para o pensamento crítico que vem de fora, vejo algum funcionalismo no CMS, algum ranço com nova roupagem. Acho que a linha de trabalho dos que estão pensando criticamente as organizações no Brasil é mais ousada, mais "guerreireana" e "tragtenbergueana" do que o main stream.

Lembro agora uma curiosidade sobre o Fernando Prestes Motta, um depoimento dele no qual se autocriticava por ter criado o termo Teoria Geral da Administração. Acho que adotei para mim, também, o exercício da autocrítica. Eu sou de uma geração na qual ser positivista era o máximo, sobretudo na Administração. Muitas vezes eu coloco o meu pensamento em julgamento. Não preciso dizer que, em geral, não o absolvo. Não reelaboraria trabalho algum que fiz do mesmo modo outra vez. Há em todos, ainda, um viés positivista muito forte. Foram cinco anos de escola de engenharia, não sei mais quantos anos estudando e ensinando geometria, portanto, eu não renego o meu viés positivista e universalista do conhecimento, apenas o submeto à crítica. O Darcy Ribeiro tem uma frase maravilhosa sobre isso, ele fala em ciências da natureza e "consciência social". Ele não fala em ciências exatas e ciência social.

As coisas mudam. Hoje as pessoas fazem mestrado e doutorado muito cedo. Isso é uma coisa nova e interessante. Quando me candidatei ao mestrado na EBAP eu tinha mais de dez anos de formado e de experiência organizacional em diversas funções. Depois, já concursado e professor naquela Escola me dei conta da dinâmica dos tempos: imagino que lá atrás fui selecionado para cursar a pós-graduação por não ser mais um menino recém-saído da faculdade, que não tem ideia do que é a dinâmica de uma organização (como muitos pósgraduandos de hoje). Então, se dava preferência para quem tivesse experiência 
organizacional, o que, com mais de dezenove anos de docência e prática da engenharia, certamente me favoreceu no processo seletivo.

\section{E FALANDO MAIS SOBRE SEUS TRABALHOS PREGRESSOS, UM TEMA QUE NÃO PODERIA DEIXAR DE ABORDAR NESSA ENTREVISTA É SUA PESQUISA SOBRE CANUDOS E ANTÔNIO CONSElHEIRO. É SABIDO QUE SE TRATA DE UM TRABALHO MUITO INTERESSANTE E AMPLAMENTE RECONHECIDO NO CAMPO DOS ESTUDOS ORGANIZACIONAIS BRASILEIROS, TENDO PROFUNDA INFLUÊNCIA EM SUA TRAJETÓRIA PESSOAL E INTELECTUAL. COMO VOCÊ CHEGOU A ESTE TEMA?}

Na verdade Antônio Conselheiro nunca chamou aquele lugar de Canudos. Esse foi um nome pejorativo, porque havia na região às margens do rio Vaza-Barris (que banha a localidade) uma vegetação canífera típica da região e que os indígenas usavam para pitar fumo, daí originando-se o nome de Canudos. Os conselheiristas nunca chamaram sua vila de Canudos. Eles organizaram uma comunidade alternativa que tinha o nome de Bello Monte e que foi de curta vida, tendo sido fundada em junho de 1893, período das festas de Santo Antônio - seu padroeiro - e tendo sido destruída e massacrada a sua população em início de outubro de 1897. Portanto, foi uma comunidade que durou, apenas, quatro anos, terminando naquele sangrento conflito.

Eu sempre tive uma curiosidade sobre essa história e confesso que conhecia muito pouco sobre Canudos, não muito mais do que a leitura de Os Sertões de Euclides da Cunha que, por sinal, é uma bela obra literária, ainda que uma fonte com forte viés inclinado às forças que massacraram o Bello Monte conselheirista.

Minha pesquisa, buscando compreender melhor o modelo de organização social daquele povoado, iniciou-se no Curso de Graduação em Administração da UFF, em 1988, no âmbito do então recém fundado Grupo de Pesquisa em História Administrativa do Brasil precursor do ABRAS -, com o projeto Canudos: Uma Experiência Auto Gestionária?, cuja primeira divulgação pública foi feita em 13 de abril de 1889, na então EBAP, para um 
seminário do Programa de Estudos Estratégicos coordenado pelo professor Luciano Zajdsznajder1, com o título A Estratégia Organizacional de Canudos.

No prefácio do meu livro A Reinvenção do Sertão os motivos que me levaram a eleger Canudos como tema de investigação são detalhados com mais profundidade.

\section{QUAIS AS PRINCIPAIS DIFICULDADES QUE VOCÊ ENFRENTOU? O FATO DE O TRABALHO VERSAR SOBRE UM OBJETO DE PESQUISA INCOMUM EM UM CURSO DE PÓS- GRADUAÇÃO EM ADMINISTRAÇÃO DEVE TER SIDO UM COMPLICADOR.}

Essa é uma história longa. Tive alguma dificuldade em conduzir e financiar o trabalho de campo. A pesquisa foi extensa, levou mais de dez anos (1988-1999). Enfrentei questões ainda não respondidas e muito relevantes para a historiografia sobre o tema. Eu buscava indicadores que apontassem que Canudos foi, também, um fato administrativo relevante.

Guiado pela ideia de que, ao contrário do que afirma a historiografia oficial, aquela comunidade sertaneja não foi produto do delírio coletivo de fanáticos mas sim um projeto de reinventar a ordem social do Sertão - tese central do meu trabalho e que está colocada de forma inequívoca na confissão de Antônio Conselheiro ao deixar o seu estado natal, respondendo a um seu conterrâneo:

- "Para onde vais Antônio?

- "Vou para onde me chamam os mal-aventurados". "Construirei 30 obras para o povo, mas estas não serão em terras do Ceará."

Havia, portanto, clara intencionalidade nas ações do construtor do Bello Monte.

\footnotetext{
${ }^{1}$ Luciano Zajdsznajder foi professor da EBAPE, trabalhando nas áreas de teoria das organizações, administração pública, sistema empresarial brasileiro e filosofia social. Graduado em Filosofia e Letras pela UFRJ, com mestrado em Economia pela Columbia University e doutorado em Comunicação Social pela Unirio. Era reconhecido pelos colegas como um pensador ousado e provocador.
} 
Sob o ponto de vista do que poderia designar como eficácia desse projeto, a minha pesquisa revela que Conselheiro concluiu 29 obras sociais (entre igrejas, capelas, restaurações de cemitérios, açudes e a fundação de dois arraiais, hoje os municípios de Crisópolis e Canudos no estado da Bahia), número este que interpreto como indicador de um projeto muito bem-sucedido. Em meu livro, antes mencionado, detalho mais sobre a obra do construtor Antônio Conselheiro nos sertões dos estados da Bahia e de Sergipe.

\section{SUA TESE ACABOU SENDO PUBLICADA NO LIVRO CHAMADO “REINVENÇÃO DO SERTÃO” QUE ESTÁ ESGOTADO FAZ UM BOM TEMPO. VOCÊ HAVIA COMENTADO QUE TEM INTERESSE EM FAZER UMA NOVA EDIÇÃO.}

Sim, eu me impus o compromisso de reeditá-lo, após mais de quinze anos que sua primeira edição se esgotou, o que aconteceu ao final de 20182. Na tese central que defendo na obra faço uma homenagem a Euclides da Cunha que, como um poeta da prosa, gostava de figuras de linguagem como oximoros, metáforas, metonímias, etc. Euclides classifica Antônio Conselheiro como sendo "um homem pelo avesso" (conforme mencionado na introdução da entrevista). Então, eu concluo que o poder político que ele tinha sobre seus liderados era o de um "coronel com sinal trocado" ou, parodiando aquele autor, de um "coronel pelo avesso". Em 2002 o professor Dawid Danilo Bartelt da Freie Universtät Berlin defendeu sua tese de doutorado em História, naquela universidade, utilizando essa mesma figura metafórica na interpretação da autoridade do Antônio Conselheiro proposta na minha tese A Reinvenção do Sertão (EAESP/FGV, 1999).

UMA COISA QUE ME CHAMA ATENÇÃO EM SUA TRAJETÓRIA, E QUE SE REFLETE TAMBÉM NA PESQUISA SOBRE BELLO MONTE, É A IMPORTÂNCIA QUE VOCÊ DÁ PARA A HISTORICIZAÇÃO DOS FENÔMENOS ADMINISTRATIVOS QUE ESTUDA. VOCÊ CHEGOU A ESTUDAR A HISTÓRIA COMO ÁREA DO CONHECIMENTO? DE ONDE VEM ESSA RELAÇÃO?

\footnotetext{
${ }^{2}$ De fato, o livro foi recentemente relançado pela editora Huicitec.
} 
Eu sou um autodidata no estudo da História. Li e leio muito sobre o assunto. É muito importante ter rigor metodológico no tratamento dos dados históricos. No meu trabalho sobre o Bello Monte faço triangulações desses dados antes de transformá-los em informação. $\mathrm{Eu}$ uso os depoimentos dos "repórteres-testemunhas" (45 depoentes no total); dos descendentes dos sobreviventes daquela tragédia (20 depoentes, 60 horas de gravação); e dos estudiosos revisionistas da historiografia sobre o tema (16 autores). Entre os primeiros, classifiquei-os em quatro subgrupos: os combatentes militares (30 no total3); os jornalistas em reportagem de campo (8 repórteres4) - aliás, o episódio Canudos inicia no Brasil o jornalismo investigativo de campo - ; o pessoal do Serviço de Saúde das forças expedicionárias federais (no total de 55); e os religiosos em missão no teatro de operações (2 sacerdotes católicos6).

Entre os documentos principais que consultei destaco os manuscritos (pregações) de Antônio Conselheiro: Apontamentos dos Preceitos da Divina Lei de Nosso Senhor Jesus Cristo, para a Salvação dos Homens (1895 e 1897). Também foi importante sua obra mais nova desaparecida, mas, felizmente, publicada por Ataliba Nogueira $\left(1978,2^{\mathrm{a}}\right.$ ed.) em formato de livro com 10 páginas fac-similadas dos originais7. Também chamo atenção para: o

${ }^{3}$ Com destaque para os: Maj. Constantino Nery, que publicou, em 1998, o primeiro livro sobre o tema; Ten. Henrique Duque-Estrada de Macedo Soares, autor de A Guerra de Canudos, publicado no mesmo ano de Os Sertões - 1902 e outros

${ }^{4}$ Entre eles: Euclides da Cunha - de A Província, depois, O Estado de São Paulo; Manoel Benicio - do Jornal do Commercio etc.

${ }^{5}$ Dentre os quais: Francisco Cavalcante Mangabeira, sextanista de medicina voluntário incorporado ao Serviço de Saúde do Exército e que publicou o seu testemunho no poema Tragédia Épica em 1900; e Alvim Martins Horcades, também acadêmico de medicina voluntário e diretor do Hospital de Sangue da tropa e correspondente do Jornal de Notícias de Salvador

6 Com destaque para o depoimento do frei João Evangelista Giuliani de Monte Marciano - enviado pelo arcebispado da Bahia à Canudos em 1895 com a missão de dissuadir os conselheiristas de sua experiência comunitária. 0 relato deste religioso (1895) é uma preciosíssima e muito rara fonte primária sobre o arraial do Bello Monte e sua organização

${ }^{7}$ Paulo Emílio destaca ainda escritos mais recentes, inéditos quando de sua investigação, finalmente publicados por Pedro Lima Vasconcellos (2017) em conjunto com os manuscritos de 1897 e notas explicativas do seu editor. 
"Passaporte do Comitê Patriótico da Bahia" (1897) - documento do arquivo familiar de descendentes de sobreviventes da tragédia de Canudos e revelado por essa pesquisa, publicado em fac-símile no meu livro A Reinvenção do Sertão, e duas cartas de Antônio Conselheiro, dirigidas aos senhores Felisberto (?) e Paulo José (?) sobre o cotidiano do arraial conselheirista, depositadas no Instituto Geográfico e Histórico da Bahia.

\section{E COMO ERAM ESSES MANUSCRITOS DO CONSELHEIRO?}

O conteúdo central desses manuscritos são pregações sobre os quatro Evangelhos e os Dez Mandamentos. Conselheiro era um beato pregador da doutrina cristã, um homem de fé que pregava a palavra de Deus; lia a Bíblia e conhecia fundamentos do latim, que estudou com o professor Manoel Antônio Ferreira Nobre na sua infância em Quixeramobim (CE). De conteúdo moralista, segundo uma doutrina católica romana conservadora e uma visão radical da Igreja de Cristo. Assim, esses manuscritos não têm grande importância para um estudioso das organizações. Há, entretanto, uma pequena parte desses documentos, que eu classificaria como política, na qual ele fala do seu projeto de vida social cristã e faz sua crítica à "república”, na visão limitada que parecia ter do regime recém implantado.

\section{FIZESTE REALMENTE UM TRABALHO ADMIRÁVEL DE PESQUISA.}

Provavelmente eu teria, hoje, no Rio de Janeiro a melhor documentação sobre Canudos e o Conselheiro. Já são mais de três décadas de estudos e buscas de informações sobre a experiência comunitária do Bello Monte e a liderança de Antônio Conselheiro e seu modelo alternativo de organização comunitária. Fiz três viagens aos sertões, rodando por aquelas terras. Fui até a minha cidade de Belém, também. Por quê? No fim do conflito o Exército estava sem condições para recrutar novos destacamentos para a ofensiva militar contra Canudos. Quatro oficiais generais haviam sido convocados para atuação nos combates. Quando o presidente Prudente de Moraes reassumiu o governo, do qual estava licenciado por razões de saúde, convocou o marechal Carlos Machado Bittencourt, ministro da guerra de então, para assumir, pessoalmente, o comando geral das tropas em operação nos sertões. A República precisava dar uma resposta definitiva à "ousadia" conselheirista e não tinha mais 
efetivos disponíveis. Esse conflito interno havia envolvido mais da metade do exército brasileiro da época.

0 governo chegou a um ponto que estava sem saber o que fazer. A força militar da Bahia já estava envolvida nos combates em Canudos desde o seu início, adjunta ao Exército. Então o governo federal fez um apelo aos estados da federação para que o socorressem com suas forças públicas estaduais. Sobre essa história, eu escrevi alguns artigos. Sendo paraense, nunca havia entendido, antes, por que havia em minha cidade natal um bairro com o nome Canudos? Por que a Polícia Militar paraense tem Canudos como uma página de glória? Em Os Sertões, Euclides da Cunha destaca a participação dessa corporação, em conjunto com a tropa do estado do Amazonas, no final dos embates e no cerco final ao arraial conselheirista.

O estado do Pará decidiu, então, enviar dois batalhões para lutar nos sertões. 0 estado do Amazonas o acompanhou com um batalhão, sob o comando do coronel Antônio Sérgio Dias Vieira da Fontoura, comandante do destacamento amazônida em missão em Canudos e patrono daquela corporação policial. Os três batalhões da Região Norte seguiram de navio até a Bahia e, ao chegar em Salvador, foram deslocados por terra para o teatro de operações, já quase ao final do conflito. Este destacamento, chegou às terras baianas em meio à situação crítica de um exército exaurido e sem condições de impor a sua força. A Amazônia vivia à época o esplendor da era da borracha. Enquanto as tropas federais se alimentavam de graxa dos canhões, Euclides nos conta sobre a pomposa chegada das tropas amazônidas à Salvador um espetáculo de ostentação e riqueza: impecáveis uniformes engalanados, instrumentos musicais dourados importados da Europa, em resumo, uma tropa esbanjando a fortuna auferida com a exportação da hevea brasiliensis deslocada de seu sítio para o massacre final e a destruição da paupérrima comunidade conselheirista da caatinga.

\section{DEVE TER SIDO MUITO INTERESSANTE ESSA PARTE DA PESQUISA SOBRE A AMAZÔNICA PARA VOCÊ QUE É PARAENSE.}

Sim, eu queria muito entender melhor a participação da Amazônia em um conflito tão distante. Pesquisei no arquivo histórico paraense as atas das reuniões do Senado Estadual do 
Pará (na época as unidades federadas replicavam localmente o sistema bicameral da União) e localizei aquela com a discussão/decisão de responder ao clamor do Governo Federal enviando tropas locais para lutar em Canudos.

Lendo essas atas eu pude compreender o que acontecia é que essa região do Brasil (com mais da metade da área total do território nacional) era totalmente isolada do restante do país. Com a economia gomífera (maior produto da pauta de exportações brasileiras da época), a riqueza e o dinheiro que rolou naquela região fez suas elites locais se europeizaram; construíram palacetes por toda a cidade e dois excelentes teatros líricos (os maiores de então nas terras brasílicas) e enviaram seus filhos para formação acadêmica nas mais famosas universidades do velho continente. As avenidas, percorridas por bondes elétricos ingleses grande modernidade de então -, eram denominadas boulevards. Não sei se essa elite era ou não separatista, como se imaginava no resto do país, mas foi nesse quadro que se criou um sentimento de resposta positiva ao pedido de socorro da República e o envio das tropas locais para o Sertão.

A minha avó paterna, a professora Maria de Nazaré Leal Uchôa Martins, contava que seu pai o dr. João Raolino Uchôa, médico formado em Paris, cidade onde viveu e clinicou por algum tempo, educou seus filhos em francês, idioma que minha avó falava fluentemente, sem jamais ter ido à França ou outro país da mesma cultura e aprendido antes da língua vernácula.

\section{MUITO INTERESSANTE. AgORA VOLTANDO PARA O LIVRO E SUA PESQUISA, A PRIMEIRA EDIÇÃO DE A REINVENÇÃO DO SERTÃo TRAZ UMA FOTO NA CAPA QUE É DO SEU ACERVO E ME PARECE QUE TEM UMA HISTÓRIA CURIOSA POR TRÁS DELA.}

Essa capa é ilustrada com uma foto das cerca de mil fotografias feitas durante a minha pesquisa de campo nos sertões (do Ceará à Bahia). Eu chegava em Canudos em 1995, pela primeira vez, e uma severa e prolongada seca assolava a região. A Canudos de hoje é uma pequena cidade ao lado do local onde o Bello Monte foi fundado. No governo Vargas foi decidido inundar aquela região com o represamento das águas do rio Vaza Barris para construir um açude voltado à irrigação da agricultura local. No período dos governos 
militares dos anos 1960-80 a velha Canudos, renascida dos escombros do Bello Monte, foi submersa nas águas do rio que outrora a banhava. Há, assim, uma narrativa de que o Bello Monte foi massacrado e incendiado pelas forças da Velha República e afogado pelo autoritarismo da ditadura empresarial-militar. A verdade é que o projeto de irrigação da região do Vaza Barris nunca floresceu.

As ruínas da igreja emergindo das águas represadas do açude de Cocorobó, que ilustra a capa da primeira edição do meu livro, foi amplamente difundida pela Imprensa, no centenário da Guerra de Canudos, como sendo obra do Conselheiro. Entretanto, a foto que batizei de "a catedral submersa do Sertão" - inspirado no prelúdio de Debussy sobre a lenda da ilha de Ys8 e de sua catedral sob as águas, e de onde soava o dobrar de seus sinos, o canto de seus monges e a música do seu órgão -, não é a mesma construída por Antônio Conselheiro mas uma segunda edição desta, provavelmente feita com as mesmas pedras/tijolos da templo conselheirista destruído e incendiado. É uma bela e sedutora foto. Ela me fala muito da história da gente sofrida do Bello Monte. Eu gosto dela e a tenho ampliada em um quadro sobre a minha cama.

\section{MAS COMO QUE VOCÊ CONSEGUIU VER E FOTOGRAFAR?}

Quando cheguei ao local pela primeira vez9 a seca prolongada castigava, mais uma vez, o Sertão. Desde que o açude de Cocorobó foi construído, nunca seu nível tinha estado tão baixo. Com a ajuda de um menino canudense e seu pequeno barco a remos navegamos por toda uma tarde pelo espelho-d'àgua daquele lago artificial, o fotografei e o filmei. Assim, a sorte me fez protagonista de um furo de reportagem com uma foto e entrevista cedidas ao jornal 0 Estado de São Paulo10. Depois, essa mesma foto esteve exposta em diversas

\footnotetext{
${ }^{8}$ Publicado em 1910, é o décimo prelúdio do Livro 1 dos Prelúdios de Debussy.

${ }_{9}^{9}$ De acordo com a Caderneta de Campo de sua investigação em 4 de fevereiro de 1995.

10 Publicadas em sua edição de 29 de março de 1995 no Caderno 2 com o título de Memória, Seca traz de volta a história de Canudos.
} 
localidades na mostra que organizei por ocasião do centenário da Guerra de Canudos e que denominei Canudos: perdão!; ainda, ilustrou revistas e livros e foi editada em vídeo, com excertos literários e sonoros sobre o tema.

Figura 1 - Capas das primeira e segunda edições do livro A Reinvenção do Sertão
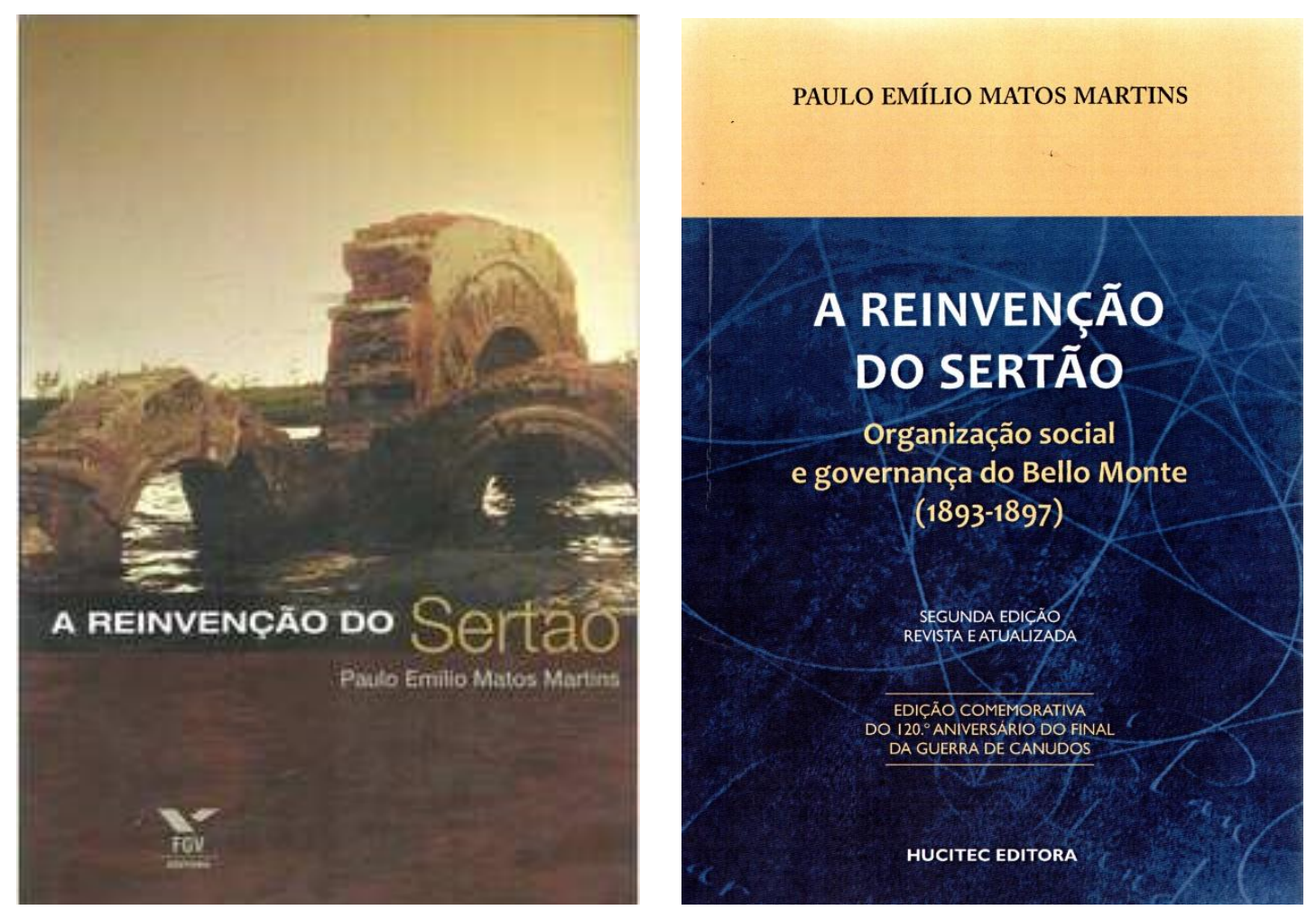

Fonte: Editora FGV, Rio de Janeiro, 2001 e Hucitec, São Paulo, 2018.

\section{E TEVE UMA REPERCUSSÃO INTERESSANTE PARA VOCÊ? ESSA PUBLICAÇÃO DE UMA REPORTAGEM?}

Foi muito boa, pois eu tive muita dificuldade para financiar minha investigação de campo (US\$ 15 mil, em valores da época) e, com o convite para apresentar a mostra fotográfica Canudos: perdão! e para palestrar sobre o tema, principalmente no ano do 
centenário daquele conflito (1997), eu pude viajar e financiar, parcialmente, o meu trabalho de pesquisa.

\section{TEM MAIS ALGUMA HISTÓRIA INTERESSANTE OU FATO DESCONHECIDO QUE VOCÊ QUEIRA CONTAR SOBRE A PESQUISA DE SUA TESE?}

$\mathrm{Na}$ última etapa da pesquisa de campo conheci Quixeramobim (CE), cidade natal de Antônio Conselheiro. Por lá entrevistei alguns parentes do reinventor do Sertão, visitei a igreja onde ele foi batizado e se casou, colhi o depoimento dos estudiosos locais do tema e visitei a casa onde nasceu, se criou e, ainda muito jovem, dirigiu o armazém herdado de seu pai - hoje Casa de Cultura de Antônio Conselheiro que eu tive o prazer de ver nascer e, junto com um grupo de valorosos jovens quixeramobienses, estudiosos da cultura e da memória de sua terra, temos trabalhado para a sua efetiva integração à vida cultural dos Estado e Município cearense como centro de pesquisa, estudos e difusão da memória local.

Ainda desse contato germinador com a cidade natal do Bom Jesus Conselheiro e sua gente ficaram: a instituição do dia 13 de março (data do nascimento do líder sertanejo) como feriado municipal de Quixeramobim, a celebração da festa Conselheiro Vivo, a construção do Memorial Antônio Conselheiro (na praça principal da cidade), com projeto do arquiteto e compositor quixeramobiense Fausto Nilo e uma série de eventos culturais e acadêmicos anuais e publicações celebrando a temática Sertão, Antônio Conselheiro e o Bello Monte.

\section{E QUAL FOI O MOMENTO DA HISTÓRIA NO QUAL CONSELHEIRO SE TRANSFORMOU EM UMA LENDA?}

Bom, depois de ser solto após prisão na Bahia, motivada pelas elites da época, ele se consolida como uma lenda entre os sertanejos, ainda que como fanático que era levou seus seguidores à morte coletiva. E aí vem o resto da história, a parte mais conhecida. Antes de ir para Bello Monte ele fundou a atual cidade de Crisópolis, antigo arraial do Bom Jesus (provavelmente, 1884). É interessante ressaltar que o beato do Sertão viveu muito mais tempo nessa localidade do que na sua Bello Monte de brevíssima existência e trágico fim. A 
igreja Matriz local, consagrada ao Bom Jesus, construída pelo Conselheiro de 1886 a 1892, conserva, em perfeito estado, um belíssimo altar de madeira talhada (fotografado e publicado em meu livro), provavelmente obra do carpinteiro do grupo, mestre Manoel Faustino (ou Feitosa?). Talvez essa seja a mais preciosa obra remanescente da arquitetura do reinventor do Sertão. Quando a visitei11, coincidentemente, na data do natalício de Euclides da Cunha, uma ordem de padres holandeses eram os párocos locais e ela estava muito bem cuidada.

Em meu livro detalho a trajetória de vida do beato do Sertão, sua peregrinação pelos estados nordestinos em que viveu e espalhou a sua doutrina, deixou suas obras públicas e sua morte no Bello Monte (1897), pouco antes da destruição do seu projeto de reinventar o Sertão.

\section{E QUANDO INICIA A BATALHA PROPRIAMENTE DITA, CONHECIDA POPULARMENTE COMO GUERRA DE CANUDOS?}

Em verdade a guerra de Canudos começa antes da intervenção das tropas federais na região. Ainda na fase de luta dos camponeses com a polícia local. No primeiro confronto os "conselheiristas" não tinham armas de fogo e se defendiam com suas ferramentas de agricultura, seus facões e umas poucas espingardas de caçar passarinhos feitas com hastes de guarda-chuvas, projetis de rochas e pólvora caseira.

Após sua prisão na Vila do Itapicuru (1876) e deportação para seu estado natal Conselheiro decide se interiorizar Sertão adentro, fugindo, assim, da perseguição dos senhores das terras daquele vale. É aí que ele decide se estabelecer e realizar o seu projeto de uma comunidade alternativa na região conhecida como Canudos. 0 motivo da escolha desse local na mais árida região da caatinga baiana tem uma dupla versão. A primeira é que lá já existia uma pequena capela abandonada, sagrada a Santo Antônio, em terras do dito Santo. Ele já havia passado por lá em suas peregrinações e imaginava que naquele local, um sítio isolado e protegido por cadeias de montanhas, estaria em segurança com sua gente. A 
segunda versão é de que em Canudos já existia um pequeno povoado e não apenas a velha capela em ruínas. 0 fato é que ele, provavelmente em junho de 1893, deixa o arraial do Bom Jesus (hoje município de Crisópolis), que fundou, acompanhado por cerca de 300 camponeses, seus seguidores, e se estabelece na região de Canudos, futuro Bello Monte, e inicia seu projeto de construção de uma sociedade fraterna e igualitária de inspiração cristã.

\section{MAS TINHA MUITO MAIS DO QUE 300 HABITANTES EM CANUDOS?}

É muito difícil definir a população do arraial em seu momento de maior desenvolvimento. Os relatos variam de 8.000 a 35.000 almas no seu apogeu. Para a minha intenção de estudar o Bello Monte como um fato administrativo era muito relevante avaliar o tamanho dessa população. Esbocei, então, uma estimativa, triangulando três métodos demográficos, e cheguei à conclusão de que lá viviam, provavelmente, 24000 habitantes no seu período áureo.

\section{E A QUESTÃo DA ORGANIZAÇÃO COMO PONTO FOCAL DA PESQUISA? COMO VOCÊ DESENVOLVEU?}

Através da justaposição dos depoimentos (discursos) dos cronistas-testemunhas do episódio, do imaginário dos descendentes dos sobreviventes do conflito e dos estudiosos do tema, principalmente os de sua corrente revisionista. 0 esquema da pesquisa foi compreender as prováveis governança e organização social do Bello Monte, a partir da dialética das dimensões mais expressivas do fenômeno: a religiosa (cristianismo sertanejo: fraternidade igualitária x gritante desigualdade social), a econômica (trabalho cooperativomutualista x escravidão e exploração) e a política (participacionismo x mandonismo coronelista).

Como estudar essas dialéticas do fato administrativo? Para tanto utilizei o modelo semiológico (Tetraedro Semiológico das Organizações) proposto na tese de doutoramento em Administração que se converteu no livro A Reinvenção do Sertão, e que analisa a semiose da 
significação das categorias estudadas (poder-autoridade-processo decisório de governança do Bello Monte e sua forma de organização) na dinâmica social no arraial conselheirista.

Dessa análise pude inferir que seria razoável entender que o projeto conselheirista de reinventar o Sertão se desenvolveu em três fases e três diferentes modelos de organização e governança assim descritos: Primeira Fase - Religiosa-Assistencial12, grupo peregrino pelos sertões; Segunda Fase - Religiosa-Administrativa-Militar13, fase da Comunidade do Bello Monte, fixação e crescimento do grupo, seu pico populacional, período de maior complexidade organizacional do movimento e estrutura colegiada de governança e do esforço bélico de defesa do Bello Monte; Terceira (derradeira) Fase - Militar14, final da guerra, destruição do Arraial e de sua organização complexa (divisão intensiva do trabalho e autoridade e governança colegiada (Colegiado do Santuário).

\section{BOM, AGORA PARA ENCAMINHARMOS O FINAL DE NOSSA ENTREVISTA, GOSTARIA DE QUE VOCÊ FALASSE UM POUCO SOBRE COMO VOCÊ VÊ AS PERSPECTIVAS PARA AS NOVAS GERAÇÕES DE ACADÊMICOS QUE DESEJAM SE ENGAJAR COM O PENSAMENTO SOCIAL BRASILEIRO E A CRÍTICA NO ESTUDOS ORGANIZACIONAIS.}

Como homem público, educador, pesquisador, professor e engenheiro, tenho sido guiado pelo ideal de construção de uma sociedade mais justa e igualitária e gostaria de ter a certeza de que o trabalho acadêmico do ABRAS, nessa senda, terá continuidade quando eu não estiver mais aqui. Pelejo para que as ideias que inspiram o nosso núcleo de estudos não desapareçam com a minha ausência. $\mathrm{O}$ que quase aconteceu com a fecunda e brilhante obra científica do nosso patrono: Alberto Guerreiro Ramos.

\footnotetext{
${ }^{12}$ Junho de 1874 a maio de 1893.

13 Junho de 1993 a junho de 1997.

14 Julho a outubro de 1897.
} 
Sou um pessimista esperançoso que, ao iniciar-me no magistério, falava para muito poucos e sonhava com uma educação crítica, capaz de formar seres humanos verdadeiramente livres e conscientes dessa condição. Hoje, suspeito que estou a falar para um público um pouquinho maior. Quem sabe (?), entre os que me ouvem, alguém empunhará essa bandeira e levará adiante o meu sonho de estudar o Brasil a partir de sua própria história e do pensamento que sobre ela reflete; de seguir lutando por uma ciência, de fato, emancipada do poder hegemônico; e de continuar acreditando que a utopia é a força que nos impulsiona para o futuro e que dá o sentido de nossas ações.

Nova Friburgo (RJ), julho de 2017.

\section{REFERÊNCIAS}

BARTELT, Dawid Danilo. Nation gegen Hinterland: der Krieg von Canudos in Brasilien: ein diskursives Ereignis. Stuttgart: Franz Steiner, 2003.

CONSELHEIRO, Antonio. Apontamentos dos preceitos da divina lei de nosso senhor Jesus Cristo, para a salvação dos homens. São Paulo: É Realizações Editora, 2017.

CUNHA, Euclides; DE CAMARGO MONFRÊ, Dermal. À margem da história. Săo Paulo: Editôra Lello Brasileira, 1967.

CUNHA, Euclides. Os Sertões. São Paulo: Três, 1984.

DOS SANTOS, Renata Pimentel. Os Sentidos do Trabalho nas Representações Sociais da Lírica da Música Popular do Brasil na Era Vargas. Dissertação (Mestrado em Mestrado Acadêmico em Administração) - Universidade Federal Fluminense, 2016.

FAORO, Raymundo. Os Donos do Poder: formação do patronato político brasileiro. Rio de Janeiro: Globo Livros, 2013.

FREYRE, Gilberto. Casa-grande \& senzala. São Paulo: Global Editora e Distribuidora, 2019. 
HOLANDA, Sérgio Buarque. Raízes do Brasil. São Paulo: Companhia das Letras, 1995.

LEAL, Victor Nunes. Coronelismo, enxada e voto: o município e o regime representativo no Brasil. Editora Companhia das Letras, 2012.

MARTINS, Paulo Emílio Matos. A Reinvenção do Sertão: organização social e poder $\mathrm{n}$ comunidade do Belo Monte (Canudos, 1893-1897). Tese (Doutorado em Administração) EAESP, Fundação Getúlio Vargas. São Paulo, 1999.

MARTINS, Paulo Emílio Matos. A reinvenção do Sertão: a estratégia organizacional de Canudos. Rio de Janeiro: Editora FGV, 2001.

SOUZA, Jessé. A tolice da inteligência brasileira: ou como o país se deixa manipular pela elite. Lisboa: Leya, 2015.

VASCONCELOS, Pedro Lima. Antonio Conselheiro por ele mesmo. São Paulo: É realizações, 2017. 